\title{
Effects of teaching planning strategies to first-grade writers
}

\author{
María Arrimada $^{1}$, Mark Torrance ${ }^{2}$ and Raquel Fidalgo ${ }^{1}$
}

\author{
${ }^{1}$ Departmento de Psicología, Sociología y Filosofía, Facultad de \\ Educación, Universidad de León. \\ ${ }^{2}$ Division of Psychology, School of Social Sciences, Nottingham Trent \\ University.
}

Word count (exc. figures/tables): 5945 words.

*Requests for reprints should be addressed to María Arrimada, Departmento de Psicología, Sociología y Filosofía, Facultad de Educación, Universidad de León, Campus de Vegazana s/n, 24071, León, España. Email: marrg@unileon.es.

\section{Acknowledgement}

Funding: This research was founded by the Spanish Ministry of Economy and Competitiveness [Ministerio de Economía y Competitividad de España], grant EDU2015-67484-P MINECO/ FEDER, awarded to the third author. The funders had no direct input into the design and implementation of the research. The first author has benefited from a research grant (FPU14/04467) awarded by the Spanish Ministry of Education, Culture and Sports (Ministerio de Educación, Cultura y Deporte de España). 


\section{Effects of teaching planning strategies to first-grade writers}

Background. Traditionally writing instruction at the start of school has focused on developing students' ability to spell and handwrite. Teaching children explicit self-regulatory strategies for developing content and structure for their text has proved effective for students in later grades of primary (elementary) education.

Aims. The present study aims to determine whether first-grade students benefit from learning higher-level self-regulating strategies for explicit planning of content and structure.

Sample. Five mixed-ability Spanish first-grade classes were randomly assigned to either an experimental condition that received strategy-focused instruction ( 3 classes, $\mathrm{N}=62$ ), or to a practice-matched control condition (2 classes, $\mathrm{N}=39$ ).

Method. Over 10, 50 minutes sessions, the intervention taught strategies for writing stories. Writing performance was assessed prior to intervention, immediately after intervention and 7 weeks post-intervention, in terms of both text features associated with written narratives and by holistic quality ratings.

Results. Students who received the intervention subsequently produced texts with better structure, coherence and quality, and a larger number of features associated with narrative texts. These effects remained at follow-up and were not present in the control condition.

Conclusion. Our findings indicate that teaching explicit strategies for planning text content and structure benefits young writers even when spelling and handwriting skills are not yet well established.

Keywords: self-regulation; planning strategy; writing instruction; primary education; text quality. 


\section{Introduction}

Learning to compose text requires development of low-level skills for translating ideas into sentences (handwriting, spelling, grammar) and knowledge of higher-level rhetorical structures that give global coherence to the text. However, this alone is insufficient: Students must also employ self-regulatory strategies that ensure that they retrieve and apply relevant knowledge in an organized and systematic way when they are faced with a writing task and specific communicative goals (Zimmerman \& Bandura, 1994). Strategy-focused writing instruction aims to teach developing writers these strategies.

Strategy-focused instruction teaches explicit planning and/or revising procedures with the aim that students will then independently use these strategies in their own writing. Strategyfocused writing instruction, as operationalised, for example, in Self-Regulated Strategy Development (SRSD: Graham \& Harris, 2018; Harris, Graham, \& Mason, 2006; Harris, Santangelo, \& Graham, 2008) typically proceeds through three stages: a) direct teaching, providing students with explicit knowledge of writing strategies, b) modelling, in which students observe the instructor modelling the target strategies, and c) emulation, when children write their own texts following the model. This approach, with some variation in detail, has been found successful in several studies. These include evaluation in struggling and typicallydeveloping students, in primary and secondary schools, in small group and whole-class context, and in different languages and educational contexts (e.g., Brunstein \& Glaser, 2011; Danoff, Harris, \& Graham, 1993; De La Paz \& Graham, 2002; Glaser \& Brunstein, 2007; Graham, Harris, \& Mason, 2005; Harris et al., 2006; Limpo \& Alves, 2013; Sawyer, Graham, \& Harris, 1992; Torrance, Fidalgo, \& García, 2007). Meta-analyses indicate that strategy-focused instruction tends to outperform other approaches to teaching writing (Graham, McKeown, Kiuhara, \& Harris, 2012; Graham \& Perin, 2007; Koster, Tribushinina, de Jong, \& van den 
Bergh, 2015; Rogers \& Graham, 2008). It is less clear exactly what mechanisms mediate the effect of this intervention (Torrance, Fidalgo, \& Robledo, 2015), although it is typically assumed that students need explicit, strategic knowledge of how to write - particularly, of procedures to plan good texts- to regulate the process by which they produce their text.

Existing evaluations of strategy focussed instruction have almost exclusively sampled students in $3^{\text {rd }}$ grade and above. Early writing instruction tends to focus almost exclusively on spelling and handwriting (Cutler \& Graham, 2008; Dockrell, Marshall, \& Wyse, 2015). The assumption has been that, until students achieve a reasonable level of mastery in these lowlevel skills, teaching strategies for planning and revising serves no function or will unnecessarily burden students. There are a handful of published studies evaluating strategyfocussed instruction for $2^{\text {nd }}$ grade writers who fail to learn at the same rate as their peers under the normal writing curriculum. These involved individualised instruction delivered one-to-one (Lane et al., 2008, 2011; Lienemann, Graham, Leader-Janssen, \& Reid, 2006) or in small groups (Harris, Graham, \& Adkins, 2015; Harris et al., 2006). Three studies involved group comparison, contrasting intervention with a normal curriculum control (Harris et al., 2015, 2006; Lane et al., 2011). The remainder were case studies. Findings suggest that, for these children, teaching planning strategies gives significant gains in text structure and overall quality in children's narrative and persuasive writing.

To our knowledge, only one previous study has evaluated strategy-focused instruction in first-grade students. Zumbrunn \& Bruning (2013) describe six single-case studies, sampling students who already demonstrated reasonable competence ${ }^{1}$ in written composition. Instruction

\footnotetext{
${ }^{1}$ Specifically, students were selected on the basis of their ability to "write independently about self-selected topics or in response to a writing prompt, express a main idea with some details, use a variety of descriptive words and phrases, identify and write complete sentences, use correct punctuation at the end of sentences, and proofread and correct for spelling errors." (Zumbrunn \& Bruning, 2013, p94). Mean age of students was 7.3 years, compared to 6.6 in the present study.
} 
was student-paced and implemented with pairs of students. Text quality, measured holistically on a 7 point scale and assessed at pre-test, post-test and follow-up, improved for all students.

The research that we report in this paper aimed to determine the effectiveness of strategy-focused instruction delivered in a fixed number of sessions by a single instructor in whole, mixed-ability first-grade classes (i.e. implemented in a form that would be possible in all typical first-grade teaching contexts). This question differs from that addressed by the studies that we have just reviewed. Previous research has established that strategy-focused instruction is effective with older students who might have a reasonable level of accuracy and automaticity in syntax, spelling and handwriting, and when delivered as an individualised, student-paced intervention to younger, struggling students. This finding does not, however, necessarily generalise to instruction for whole classes of younger students.

It is possible that teaching planning strategies prematurely will not benefit and may even hinder writing development. Written production is cognitively demanding, with various processes competing for limited cognitive capacity (McCutchen, 1996; Torrance \& Galbraith, 2006). Fayol (1999) argued that in young children cognitive resources are mostly devoted to orthographic and grapho-motor processing, leaving little spare capacity for higher-level processing. Having to learn and remember an explicit planning strategy is, in itself, resourcedemanding and potentially diverts resources from transcription. Rijlaarsdam and co-workers (Rijlaarsdam et al., 2011; Rijlaarsdam \& Couzijn, 2000) describe the "double challenge" faced by students when they are required to learn a new writing strategy concurrently with performing demanding writing tasks. More directly, it may simply be that students who struggle to compose sentences are motivationally not ready to learn about how to apply higherlevel structure to their text. 
It is, however, also possible to make a resource-demand argument in favour of early planning-strategy instruction: It may be that teaching planning strategies, if done appropriately, reduces the cognitive load. By introducing discrete pre-planning or "stop and think" activities into the writing process, students can separate out the processing of higher-level text features from word and sentence production, thus reducing potential competition (Kellogg, 1988, 1990). Also, teaching students how to plan and structure text before they have mastered transcription is not necessarily demotivating. The genre-related characteristics of narrative text can, in principle, be learned independently of the ability to instantiate narratives with these characteristics on the page. Nemirovsky (2009) argued that teaching content and rhetoric - the social function of written language - promotes meaningful learning. Teaching children to play the role of authentic communicators is, in itself, motivating (Teberosky \& Sepúlveda, 2009). The attention and effort devoted to a writing task is highly motivation-dependent (Bruning \& Horn, 2000; Pajares, 2003). Interventions that increase students' enthusiasm for writing will increase opportunity for learning both high- and low-level skills.

In summary, existing research has established the benefit of teaching explicit strategies for generating and structuring content to children across a full-range of abilities at and above third grade. Younger children, who are unlikely to have achieved automaticity in transcription, may or may not benefit in the same way. The study we report in this paper therefore addresses the following research question: Does first-grade students' narrative-composition performance improve as a result of teaching explicit procedures for planning content and structure?

We implemented and evaluated a strategy-focused instructional program with mixedability classes of Spanish children in the second trimester of their 1st grade. The intervention was based in Cognitive Self-Regulation Instruction - a strategy-focused approach to writing instruction similar to SRSD - that has been demonstrated to have positive and sustained effects 
in $6^{\text {th }}$ grade children (Fidalgo, Torrance, \& García, 2008; Fidalgo, Torrance, Rijlaarsdam, van den Bergh, \& Álvarez, 2015; López, Torrance, Rijlaarsdam, \& Fidalgo, 2017; Torrance et al., 2007). Writing performance was evaluated in controlled tasks prior to intervention, immediately following intervention, and at seven weeks. Texts from these tasks were evaluated in terms of holistic (reader-based) quality measures and by counts of linguistic features associated with good narrative texts. If first-grade students benefit from strategy-focused instruction, we predict greater and sustained increase in scores on both of these measures, relative to practice-matched controls.

\section{Method}

\section{Design}

Five existing first-grade classes were randomly allocated to either intervention or control conditions. Students in the intervention condition were taught planning strategies through a strategy-focused instructional program. Students in the control condition engaged in activities targeting their understanding of story structure and to increase motivation for story writing. Instruction for both conditions was delivered by a researcher who is also a trained teacher (the first author). Both groups completed the same number of writing tasks. Students performed controlled writing tasks before intervention and immediately after intervention, and then were followed up in a delayed post-test. Time between the end of the intervention and follow-up varied between 52 and 56 days, with a mean of 55 days for the intervention condition and 54 days for controls. Both evaluation tasks and instruction focused on story writing.

\section{Participants}

Five first-grade classes (101 children, 54 female) across 2 concertados schools in León (Spain), participated in the study. From a total of 110 students, 7 were removed from the sample 
(5 intervention, 2 controls) because they did not complete all the writing assessments; and 2 (1 intervention, 1 control) because teachers identified them as having broad ranging and substantial developmental delay that prevented them from engaging in the intervention activities. Table 1 provides sample details. The intervention was conducted during the second trimester of the academic year (from January to March).

[insert Table 1 near here]

\section{Educational and Language context}

In the Spanish school system, education is not compulsory until first grade (6 years old). However, children who attend kindergarten, which was true for all participants in this study, receive some formal writing instruction. This focuses on letter name, shape and sound, and the writing of some simple words, mostly through copy tasks. At the end of kindergarten, most children are able to sound and write all the letters and short words with simple syllable structure (consonant + vowel). These skills are revisited during the first trimester of first grade. Students are also introduced to dictation tasks, capital letters and some spelling rules (c / z and c / q distinctions).

Instruction in phoneme-grapheme correspondence is a particular focus of early writing instruction in Spain. Nearly all words have regular spelling (straightforward phonemegrapheme correspondence) which makes it quicker to move from letter sounds to the writing of words that would be the case in deep orthographies.

\section{Instructional programs}

Differences between intervention and control conditions are summarized in Table 2. Both programs were applied over 10 twice-weekly sessions lasting between 45 to 55 minutes, delivered to whole-class groups. Control and intervention conditions were matched in terms of 
the amount of writing practice - time in completing a narrative writing task - that children received.

[insert Table 2 near here]

\section{Planning-strategy instruction}

The intervention design drew heavily on previous strategy-focused interventions, particularly Cognitive Self-Regulation Instruction (Fidalgo \& Torrance, 2018; Fidalgo, Torrance, Robledo, \& García, 2009), but with adaptations to make the instruction appropriate for younger writers. First-grade students typically struggle to produce written outlines for their text (Limpo, Alves, \& Fidalgo, 2014). We therefore taught strategies that required "thinking before writing" but that encouraged incremental planning- transcription cycles rather than focusing all attention on a distinct planning phase prior to transcription. Instructional strategies were adapted to younger learners: where previous interventions have taught mnemonics based around acronyms to help students retain declarative knowledge of specific writing strategies, the present intervention used a puppet and a picture of a mountain as the central mnemonic device. This retained younger students' attention and motivation, and removed the additional load imposed by the need to memorise an acronym, thus reducing the "double challenge".

The intervention program focused on the structural parts of a narrative: introduction, development and conclusion. This structure is typically taught in Spanish elementary school textbooks, but its detail closely parallels the "situation, complication, resolution and coda" structure (Labov, 1972). The program was delivered in 3 phases: direct strategy teaching, modelling and individual practice. Direct strategy teaching comprised 5 sessions focused on providing students with explicit knowledge about planning processes and the structural elements of a narrative. In Session 1 students were reminded of the importance and purpose of writing. They were then taught a specific planning strategy, using a puppet called Pensarín 
(Pensar $=$ 'to think'). Students were instructed to recall Pensarín's name each time they write a story, since it reminds them to think carefully about what they are going to write. The next three sessions were devoted to direct teaching of the main parts of a narrative: introduction, development and conclusion. At the beginning of each session, students were reminded about the planning process through Pensarín's name. Then, the instructor introduced "La Montaña de los Cuentos" ("Story Mountain", appendix A), the mnemonic used to help students learn and retain explicit knowledge of story structure. Different sessions focused on introduction, development and conclusion, each represented by different villages on the road up the mountain. Students were taught the elements of that part of the text, represented as stickers shaped like houses. Introduction was represented by 3 houses: when the story happens, where it happens and who the main characters are. Development comprised what happens to the characters and how they react to these events. Finally, conclusion explained how the story ends. At the end of each session, stickers representing structural elements were removed and students placed them again correctly to aid retention of the strategy. Session 5 was devoted to reading and discussing two texts: one was a complete narrative, including all the taught elements, and the other omitted a number of features. Initially, students recalled the planning strategy and the narrative structure. They were then given a complete text, which the instructor read aloud, and were asked to judge whether it included all the structural elements. The procedure was then repeated with a story that had missing features.

The second phase, modelling, comprised 4 sessions focused on providing students with a mastery model of a writer applying the planning strategy taught. This involved the instructor "thinking aloud" in front of the class while writing a story. Think-aloud was semi-scripted. Given the students' age, and therefore likely inability to sustain attention, modelling was combined with some guided writing practice. In Session 6, children initially recall the planning 
strategy and the elements of a proper introduction. The instructor then modelled how to plan and write a good introduction. During this process, the instructor emphasized the steps to follow in the writing process (e.g., "What was the first part of the mountain? Oh, it was "introduction", so the first part of my tale should be the introduction") and expectations of success (e.g., "using everything I've learnt, I'll write an amazing story"). Next session was devoted to students writing their own introduction, following the procedure previously observed. Sessions 8 and 9 followed the same pattern but focused on the development and the conclusion of a story.

The final session focused on individual practice in which students wrote their own stories. Students wrote a narrative without seeing the mountain, using everything they had learnt. The instructor patrolled the class providing encouragement and occasional feedback on surface features of the text, but did not comment on content or structure.

\section{Control Condition}

Students in the control condition received a program of largely play-based activities based around narratives. Their writing practice was matched to the intervention in terms of number of writing tasks and time spent writing. Sessions were guided by the same puppet used with the intervention condition, though no importance was attached to the puppet's name. Children did not receive explicit instruction on how to plan text or on the structural elements of a narrative. In session 1 the importance and purpose of writing were discussed in the same way as in the intervention condition. Students then told their favourite stories. Sessions 2 and 6 were devoted to reading comprehension, with the instructor reading a story and asking children questions about its content (i.e "what happened at the beginning?" "how could you change the end?"). Sessions 3, 5 and 10 were devoted to play-based activities aimed at increasing students' writing motivation. Sessions 4 and 9 focused on individual story writing to practice-matched 
the experimental program. Session 8 was devoted to practice transcription skills through copy tasks. In session 7, children visited the school library with the aim of understanding the social function of writing.

\section{Measures}

All students completed narrative writing tasks at pre-test, post-test and follow-up. Students were free to choose the topic. The instructor told the students: "From now until I tell you to stop, you are going to write a story about whatever you want. You can make it up or recall one that already exists ${ }^{2}$. Think carefully about what you are writing. I'll read your narratives and show them to professors at university, so please, write as clearly as you can, making wonderful letters so that the people from university and I can understand your handwriting". Students were given a maximum of 40 minutes to complete the task. Texts were assessed with both text-based (text-linguistic) and reader-based measures.

\section{Reader-based (holistic) text ratings}

Reader-based holistic ratings were given for structure, coherence and overall quality (see appendix B for example compositions), based on a rating scheme adapted from that described by Spencer and Fitzgerald (1993).

Structure was assessed on a 4-point scale, with 1 indicating lack of discernible structure and 4 being well structured. The score was based on the extent to which pupils created a global framework to place the story, used connectors, mentioned the initial event, included characters' response to events and results obtained from characters' actions and established a temporal or causal relationship between events.

\footnotetext{
${ }^{2}$ In response to reviewers' comments we explored whether conditions varied in the extent to which students made up their own narratives. Texts were coded as either "mainly invented / story unfamiliar to the raters" or "story contains main elements that are familiar to the raters". At pre-test, 37 intervention students $(59.7 \%)$ and 25 control (64.1\%) wrote a mainly invented story / unfamiliar story. At post-test, 56 intervention stories $(90.3 \%)$ and 36 control (92.3\%) were mainly invented. At follow-up, 55 intervention students (88.7\%) and 33 control (84.6) made up their stories.
} 
Coherence was assessed on a 4-point scale, with 1 given to incoherent texts and 4 for texts that were mainly or entirely coherent. This score was based on whether it was possible to identify the main topic, there was a clear development without entanglements, the text provided a clearly-defined general context, details were organized, the use of cohesion markers, fluent speech and for the existence of a conclusion.

Overall Quality was assessed on a 6-point scale, with 1 meaning incomprehensible and 6 very good. The score was based on the presence of a clear sequence of ideas with little or no irrelevant details, good global organization, suitable vocabulary, a variety of interesting details, correct sentence structure and correct punctuation and spelling.

\section{Text-linguistic evaluation}

Text-based measures involved identifying, within the text, organizational structures that are typically associated with written narratives, following Cuetos, Sánchez and Ramos (1996). We rated both framework and episode.

Framework included references to time, space and characters. One point was given for each temporal or spatial reference. For example, if a child wrote "Yesterday, at $9.00 \mathrm{pm}$, I was at home when...", then, they were given 2 points for temporal references and 1 point for a space reference. Characters were scored with 1 point if they were just named or listed ("One day, a princess was...”) or 2 points if the children mentioned some of their physical or psychological features (“One day, a beautiful and friendly princess was...”). These scores were then summed.

Episode included the initial event, characters' emotional reactions to any happenings in the story, actions performed by the characters and consequences. Children were given 1 point if they wrote about an initial event ("Little Red Riding Hood's mother told her to go to her grandma's"). Then, we gave 1 point for each action and emotional reaction mentioned by the 
children. For example, in the sentence "The wolf looked for the little girl but he did not find her, so he felt disappointed and sad" the child would be given 1 point for the action and 2 points for the reactions. Finally, consequences were scored with 1 point if they were mentioned ("The spell was finally broken, and the princess could marry the prince"). Scores were then summed.

All texts were scored by two independent raters, both blind to condition and to assessment (pre-test, post-test, follow-up). Interrater agreement, across all product measures and assessments, gave a mean of .94 (framework $=.91 ;$ episode $=.98 ;$ structure $=.94 ;$ coherence $=$ .93 ; quality $=.95$ ) indicating reliability of the measures.

\section{Text length}

We also measured text length (number of words written by the children, excluding those that were crossed out).

\section{Results}

We conducted separate analyses comparing scores at pre-test vs. post-test and at pre-test vs. follow-up. Data were analysed using linear mixed effects models (e.g. Quené \& van den Bergh, 2004) with random by-student and by-class intercepts and test (pre-test vs. post-test, or pre-test vs. follow-up), condition (control, intervention), and the condition-by-test interaction as fixed factors. Models were implemented in LME4 (Bates, Mächler, Bolker, \& Walker, 2015) with maximum likelihood estimation. Intra-class correlations are reported in Appendix C. We evaluated statistical significance by F-test using the Satterthwaite approximation for denominator degrees of freedom. We report standardized effect sizes calculated as the difference between estimated means, at post-test, and at follow-up, for the control and intervention conditions divided by total error variance ( $d_{T}$, Hedges, 2007).

If strategy-focused instruction benefitted students then we would expect to see an increase in scores between pre-test and post-test in the intervention group, and that this increase would 
be greater than in the control group. If effects of intervention were enduring, then we would expect to see an increase in the intervention condition between pre-test and follow-up, and again that this increase would be greater than in the control condition. The effectiveness of the intervention is therefore established by finding a significant interaction between test and condition. In all cases where we claim a significant effect values for $p$ were less than the value of alpha after Bonferroni correction for familywise error rate (.05/6).

Scores on all five writing performance measures were approximately normally distributed. Text length was positively skewed, but approximately log-normal, and so was transformed prior to analysis. Bivariate correlations among measures are reported in Table 3. The three holistic measures were highly correlated, indicating weak discriminant validity. Correlation between the two text-based measures and between these measures and the holistic quality ratings were, however, less, suggesting better discrimination.

Mean scores by condition and test occasion can be found in Figure 1.

[insert Table 3 and Figure 1 near here]

\section{Effects on reader-based (holistic) ratings}

As can be seen from Figure 1 there was a substantial increase in the intervention group between pre-test and post-test in all three holistic measures of text quality. We did not observe similar changes in the control group. The interactions between condition (control, intervention) and test (pre, post) were statistically significant for all three measures (Structure, $F(1,99)=$ 43.2, $p<.001$; Coherence, $F(1,99)=20.6, p<.001 ; F(1,99)=24.2, p<.001$; effect sizes, Structure, 1.4; Coherence, 1.0; Quality, 1.5). Effects persisted at the seven-week follow-up. The test by condition interaction remained significant for all three measures (Structure, $F(1,99)$ 
$=9.4, \mathrm{p}=.003$; Coherence, $F(1,99)=18.7, p<.001$; Quality, $F(1,99)=15.8, p<.001 ;$ effect sizes, Structure, .9; Coherence, 1.0; Quality, 1.3).

\section{Effects on text-linguistic evaluation}

Text-based assessment showed similar effects to the holistic text ratings, although these were weaker, particularly in terms of the extent to which students included reference to time, space, and character in their narratives (the Framework measure). Students in the intervention condition improved in both Framework and Episode scores between pre-test and post-test and there was statistically significant improvement in both scores, relative to control (Framework, $F(1,99)=3.91, p=0.05$; Episode, $F(1,99)=16.7, p<.001$ for the test by condition interaction; effect sizes, Framework, .93; Episode, 3.0). The effect on Episode scores remained at followup significant $\left(F(1,99)=7.08, \mathrm{p}=.009, d_{T}=2.2\right)$. However, the effect on Framework was not sustained at follow-up $(F(1,99)=2.15, p=0.15)$. It should also be noted that Framework scores were significantly different at pre-test, as can be seen from Figure 1, with students in the intervention group scoring higher than students in the control condition. This lack of sustained effect and of equivalence between groups at baseline suggest that apparent effects of intervention on Framework should be treated with caution.

\section{Effects on text length}

Both the intervention and control groups wrote longer texts at post-test and at follow-up, relative to pre-test. However, we found no evidence that increases were greater in the intervention condition $(F<1$ at post-test and $F(1,99)=1.31$ at follow-up for the test by condition interaction).

\section{Discussion}

The present study aimed to determine whether very early writers, who are unlikely to have developed any level of automaticity in spelling and handwriting, benefit from strategies for 
planning the content and structure of their text. Our findings provide evidence that this is the case. After instruction, intervention students' stories were more coherent, had better structure, included more sophisticated narrative content (the Episode measure), and were rated as having higher overall quality than those produced by students in the control group. These benefits were present immediately after intervention and sustained at least in the medium term.

Previous research has demonstrated the efficacy of planning strategy instruction for elementary students who have achieved reasonable competence in handwriting and spelling (Harris et al., 2012a, 2012b; Limpo \& Alves, 2014; Tracy, Reid, \& Graham, 2009; Zumbrunn \& Bruning, 2013) and with small groups of second-grade struggling writers (Harris et al., 2006, 2015; Lane et al., 2008, 2011; Lienemann et al., 2006). Our findings suggest that this extends to whole, mixed-ability classes of students at the very beginning of primary education, when transcription skills are poorly developed. This is counter to the argument that focussing instruction on higher-level text features before skills necessary to generate sentences have been mastered will overload students to the detriment of their learning and writing.

Our findings suggest, therefore, strong and sustained benefits for students at a very early stage of writing development learning explicit content and structure planning strategies. This conclusion should be qualified in several ways.

First, delayed post-test was only seven weeks post-intervention. In previous research, effects of a similar intervention have been found in 6th grade children at 12 weeks and even two years after they had returned to typical, product-focused, writing instruction (Fidalgo et al., 2008; Torrance et al., 2007). Had our follow-up been more delayed, effects might have been lost. Arguably, however, in the present context this would not be evidence against the efficacy of learning planning strategies. Given the developmental stage of the students, we would not expect effects to be maintained without classroom reinforcement. Our study shows 
that planning-focused instruction can be effective beyond effects that were present immediately after intervention. This alone is, we believe, sufficient evidence to support incorporating planning-focused instruction into classroom practice, sustained throughout the school year.

Second, our study, in common with most previous evaluations of strategy-focused writing instruction, does not provide strong evidence of mechanism. We do not know, for example, whether the effects of intervention are due to children adopting planning strategies or to them developing knowledge about the structure of good narratives, or both. Evidence suggests that when older children are taught explicit planning strategies they independently apply these when composing their texts (Armengol, 2007; Fidalgo et al., 2009, 2015). The process measures necessary to explore children's use of the procedures that they were taught are not easily obtained from the very early writers sampled in this study. From a classroom practice point of view, mechanism is probably unimportant. However, there is some evidence that teaching outlining strategies to older children may extend writing time without associated gains in text quality (Torrance et al., 2015).

Another possible explanation for our findings is that effects were achieved just by increasing students' motivation for writing. This would in itself have educational value, and it is probably the case that writing performance in very early writers is particularly motivationdependent. However, there are three reasons to believe that effects of intervention went beyond increasing motivation. First, there is no particular reason why the intervention condition was more motivating than the control. Unlike "business as usual" control conditions often used in previous research, the control condition in this study deliberately involved activities designed to demonstrate that writing is valuable and enjoyable. Second, effects were sustained at seven weeks, after all students had returned to the same, transcription-focused writing instruction. Third, we would expect increased motivation to result in increased productivity. If intervention 
students were simply more motivated, we would expect them to write longer texts than their peers. Previous evaluations of strategy-focused instruction, across a range of ages, have varied in whether or not they have found effects on text length (No effect: Fidalgo et al.,2009; Harris et al., 2012a, 2012b; Torrance et al., 2007; Torrance et al., 2015. Effect: Graham et al., 2005; Limpo \& Alves, 2014; Tracy et al., 2009). The present study found no effect. It seems probable, therefore, that the positive effects of intervention in the present study resulted from students learning how to plan narrative texts and then regulating their own writing behaviour, applying what they had learned to how they wrote. Writing performance increased not as a result of longer texts, but because what they wrote was thematically and rhetorically more sophisticated.

A third qualification is that we do not have strong evidence for the efficacy of each of the individual instructional components that comprised the intervention. It may be for example, that modelling or declarative instruction alone is sufficient to achieve similarly large effects. There is evidence from interventions with older children to support both of these positions (Fidalgo et al., 2015; López et al., 2017; Sawyer et al., 1992). Application of the full program implemented in the present study is relatively time-consuming and effortful, and omitting redundant components is desirable. Research is needed, therefore, that isolates and evaluates, within very early writers, the various instructional components.

Finally, although our study provides robust evidence of an increase in average performance across mixed-ability classes, our results do not answer question about whether the intervention worked for children with particularly low (or high) ability. Research cited above has shown benefits of similar interventions with struggling second graders but literacy develops rapidly during the first two years of school, and it is possible that similar effects would not be found in first grade (but see Arrimada, Torrance, \& Fidalgo, 2018). 
The educational and language context for this study should be borne in mind when generalising from our findings. Students in this study were writing in a shallow orthography and had all received some handwriting and spelling instruction in kindergarten. Therefore although they will not have achieved a high level of transcription automaticity, it was reasonable to expect them to be able to write sufficient words to at least attempt to write a story, and also to guess spellings for words that they had not previously written. It may be the case in languages where spelling is less regular and / or with children for whom first grade is their very first contact with handwriting and spelling, that strategy-focussed instruction is less effective. There is, however, no in-principle reason why the higher-level skills taught in the present intervention should not be taught, in modified form, to children who have no transcription ability, with children practicing orally or by dictation.

In conclusion, our study suggests that, when appropriately adapted, instruction that focusses on developing explicit strategies for planning the content and structure of narrative texts has benefits even for writers who are far from gaining automaticity in handwriting and spelling. This suggests that it is possible for young writers to divide their attention between high and low-level writing processes without competition or, at minimum, that the negative effects of any competition that occurs are outweighed by the benefits of giving explicit attention to planning content and structure. More generally, our findings suggest that even very young writers are typically able not only to comprehend and retain meta-linguistic representations about text structure, but also to strategically apply this knowledge to their own writing. There appears, therefore, to be value in teaching students strategies for planning the content and structure of their text from the start of their writing career. 


\section{References}

Armengol, L. (2007). Los protocolos de pensamiento en voz alta como instrumento para analizar el proceso de escritura. RESLA, 20, 27-35.

Arrimada, M., Torrance, M., \& Fidalgo, R. (2018). Supporting first-grade writers who fail to learn: multiple single-case evaluation of a Response to Intervention approach. Reading and Writing. https://doi.org/10.1007/s11145-018-9817-x

Bates, D., Mächler, M., Bolker, B., \& Walker, S. (2015). Fitting Linear Mixed-Effects Models Using lme4. Journal of Statistical Software, 67(1). https://doi.org/10.18637/jss.v067.i01

Bruning, R., \& Horn, C. (2000). Developing motivation to write. Educational Psychologist, 35(1), 25-37. https://doi.org/10.1207/S15326985EP3501

Brunstein, J. C., \& Glaser, C. (2011). Improving writing competence in fourth-grade classrooms: Effects of a teacher-implemented self-regulated writing program on students' strategy-related knowledge, planning skills, and writing performance. Journal of Educational Psychology, 103(4), 922-938.

Cuetos, F., Sánchez, C., \& Ramos, J. L. (1996). Evaluación de los procesos de escritura en niños de educación primaria. Bordón, 48(4), 445-456.

Cutler, L., \& Graham, S. (2008). Primary Grade Writing Instruction: A National Survey. Journal of Educational Psychology, 100(4), 907-919. https://doi.org/10.1037/a0012656

Danoff, B., Harris, K., \& Graham, S. (1993). Incorporating strategy instruction within the writing process in the regular classroom: Effects on the writing of students with and without learning disabilities. Journal of Reading Behaviour, 25(3), 295-322. https://doi.org/10.1080/10862969009547819

De La Paz, S., \& Graham, S. (2002). Explicitly teaching strategies, skills, and knowledge: Writing instruction in middle school classrooms. Journal of Educational Psychology, 
94(4), 687-698. https://doi.org/10.1037//0022-0663.94.4.687

Dockrell, J. E., Marshall, C. R., \& Wyse, D. (2015). Teachers' reported practices for teaching writing in England. Reading and Writing, 29(3), 409-434. https://doi.org/10.1007/s11145-015-9605-9

Fayol, M. (1999). From on-line management problems to strategies in written composition. In M. Torrance \& G. Jeffery (Eds.), The cognitive demands of writing: processing capacity and working memory effects in text production (pp. 15-23). Amsterdam: Amsterdam University Press.

Fidalgo, R., \& Torrance, M. (2017). Developing writing skills through cognitive self-regulation instruction. In R. Fidalgo, K. Harris, \& M. Braaksma (Eds.), Desig principles for teaching effective writing (pp. 89-118). Leiden: Brill Editions.

Fidalgo, R., Torrance, M., \& García, J. N. (2008). The long-term effects of strategy-focussed writing instruction for grade six students. Contemporary Educational Psychology, 33(4), 672-693. https://doi.org/10.1016/j.cedpsych.2007.09.001

Fidalgo, R., Torrance, M., Rijlaarsdam, G., Van den Bergh, H., \& Álvarez, M. . (2015). Strategy-focused writing instruction: Just observing and reflecting on a model benefits 6th grade students. Contemporary Educational Psychology, 41, 37-50. https://doi.org/10.1016/j.cedpsych.2014.11.004

Fidalgo, R., Torrance, M., Robledo, P., \& García, J. (2009). Dos enfoques metacognitivos de intervención: auto-conocimiento del producto textual frente a auto-regulación del proceso de escritura. International Journal of Developmental and Educational Psychology, 1(1), $313-321$.

Glaser, C., \& Brunstein, J. C. (2007). Improving fourth-grade students' composition skills: Effects of strategy instruction and self-regulation procedures. Journal of Educational 
Psychology, 99(2), 297-310. https://doi.org/10.1037/0022-0663.99.2.297

Graham, S., \& Harris, K. (2018). Evidence-Based Writing Practices: a Meta-Analysis of existing meta-analysis. In R. Fidalgo, K. Harris, \& M. Braaksma (Eds.), Design principles for teaching effective writing: theoretical and empirical grounded principles. Leiden: Brill Editions.

Graham, S., Harris, K., \& Mason, L. (2005). Improving the writing performance, knowledge, and self-efficacy of struggling young writers: The effects of self-regulated strategy development. Contemporary Educational Psychology, 30(2), 207-241. https://doi.org/10.1016/j.cedpsych.2004.08.001

Graham, S., McKeown, D., Kiuhara, S., \& Harris, K. (2012). A meta-analysis of writing instruction for students in the elementary grades. Journal of Educational Psychology, 104(4), 879-896. https://doi.org/10.1037/a0029185

Graham, S., \& Perin, D. (2007). A Meta-Analysis of Writing Instruction for Adolescent Students. Journal of Educational Psychology, 99(3), 445-476. https://doi.org/10.1037/0022-0663.99.3.445

Harris, K, Lane, K.L., Driscoll, S.A., Graham, S., Wilson, K., Sandmel, K., Brindle, M., \& Schatschneider, C. (2012). Tier 1 , t e a c h e r - i m p l e m e n t e d self-regulated and without challenges. The Elementary School Journal, 113(2), 160-191. https://doi.org/10.1086/667403

Harris, K., Graham, S., \& Adkins, M. (2015). Practice-based professional development and Self-Regulated Strategy Development for Tier 2, at-risk writers in second grade. Contemporary Educational Psychology, 5-16. https://doi.org/10.1016/j.cedpsych.2014.02.003

Harris, K., Graham, S., \& Mason, L. (2006). Improving the writing, knowledge, and motivation 
of young struggling writers: Effects of self-regulated strategy development with and without peer support. American Educational Research Journal, 43(2), 295-340. https://doi.org/10.3102/00028312043002295

Harris, K., Lane, K. L., Graham, S., Driscoll, S. A., Sandmel, K., Brindle, M., \& Schatschneider, C. (2012). Practice-Based Professional Development for Self-Regulated Strategies Development in Writing: A Randomized Controlled Study. Journal of Teacher Education, 63(2), 103-119. https://doi.org/10.1177/0022487111429005

Harris, K., Santangelo, T., \& Graham, S. (2008). Self-regulated strategy development in writing: Going beyond NLEs to a more balanced approach. Instructional Science, 36(56), 395-408. https://doi.org/10.1007/s11251-008-9062-9

Hedges, L. V. (2007). Effect Sizes in Cluster-Randomized Designs. Journal of Educational and Behavioral Statistics, 32(4), 341-370. https://doi.org/10.3102/1076998606298043

Kellogg, R. T. (1988). Attentional overload and writing performance: Effects of rough draft and outline strategies. Journal of Experimental Psychology: Learning, Memory, and Cognition, 14(2), 355-365. https://doi.org/10.1037/0278-7393.14.2.355

Kellogg, R. T. (1990). Effectiveness of Prewriting Strategies as a Function of Task Demands. The American Journal of Psychology, 103(3), 327-342. https://doi.org/10.2307/1423213

Koster, M., Tribushinina, E., de Jong, P. F., \& van den Bergh, H. (2015). Teaching children to write: A meta-analysis of writing intervention research. Journal of Writing Research, 7(2), 249-274. https://doi.org/10.17239/jowr-2015.07.02.2

Lane, K., Harris, K. ., Graham, S., Weisenbach, J. ., Brindle, M., \& Morphy, P. (2008). The Effects of Self-Regulated Strategy Development on the Writing Performance of SecondGrade Students With Behavioral and Writing Difficulties. The Journal of Special Education, 41(4), 234-253. https://doi.org/10.1177/0022466907310370 
Lane, K., Harris, K., Graham, S., Driscoll, S., Sandmel, K., Morphy, P., ... Schatschneider, C. (2011). Self-Regulated Strategy Development at Tier 2 for Second-Grade Students With Writing and Behavioral Difficulties: A Randomized Controlled Trial. Journal of Research on Educational Effectiveness, 322-353. https://doi.org/10.1080/19345747.2011.558987

Lienemann, T. O., Graham, S., Leader-Janssen, B., \& Reid, R. (2006). Improving the Writing Performance of Struggling Writers in Second Grade. The Journal of Special Education, 40(2), 66-78. https://doi.org/10.1177/00224669060400020301

Limpo, T., \& Alves, R. A. (2013). Teaching planning or sentence-combining strategies: Effective SRSD interventions at different levels of written composition. Contemporary Educational Psychology, 38(4), 328-341. https://doi.org/10.1016/j.cedpsych.2013.07.004 Limpo, T., \& Alves, R. A. (2014). Implicit theories of writing and their impact on students' response to a SRSD intervention. The British Journal of Educational Psychology, 84(4), 571-590. https://doi.org/10.1111/bjep.12042

Limpo, T., Alves, R. A., \& Fidalgo, R. (2014). Children's high-level writing skills: development of planning and revising and their contribution to writing quality. The British Journal of Educational Psychology, 84(2), 177-193. https://doi.org/10.1111/bjep.12020

López, P., Torrance, M., Rijlaarsdam, G., \& Fidalgo, R. (2017). Effects of Direct Instruction and Strategy Modeling on Upper-Primary Students 'Writing Development. Frontiers in Psychology, 8, 1-10. https://doi.org/10.3389/fpsyg.2017.01054

McCutchen, D. (1996). A capacity theory of writing: Working memory in composition. Educational Psychology Review, 8(3), 299-325. https://doi.org/10.1007/BF01464076

Nemirovsky, M. (2009). Experiencias escolares con la lectura y la escritura. In M. Nemirovsky (Ed.), La escuela: espacio alfabetizador (pp. 11-32). Barcelona: Graó. 
Pajares, F. (2003). Self-efficacy beliefs, motivation, and achievement in writing: A review of the literature. Reading and Writing Quarterly, 19(2), 139-158. https://doi.org/10.1080/10573560390143085

Quené, H., \& van den Bergh, H. (2004). On multi-level modeling of data from repeated measures designs: a tutorial. Speech Communication, 43(1-2), 103-121. https://doi.org/10.1016/j.specom.2004.02.004

Rijlaarsdam, G., \& Couzijn, M. (2000). Writing and learning to write: A double challenge. New Learning, 157-189.

Rijlaarsdam, G., Van den Bergh, H., Couzijn, M., Janssen, T., Braaksma, M., Tillema, M., ... Raedts, M. (2011). Writing. In S. Graham, A. Bus, S. Major, \& L. Swanson (Eds.), Handbook of educational Psychology: application of educational psychology to learning and teaching (pp. 189-228). Washington, D.C.: American Psychlogical Society.

Rogers, L. A., \& Graham, S. (2008). A Meta-Analysis of Single Subject Design Writing Intervention Research. Journal of Educational Psychology, 100(4), 879-906. https://doi.org/10.1037/0022-0663.100.4.879

Sawyer, R. J., Graham, S., \& Harris, K. (1992). Direct teaching, strategy instruction, and strategy instruction with explicit self-regulation: Effects on the composition skills and self-efficacy of students with learning disabilities. Journal of Educational Psychology, 84(3), 340-352. https://doi.org/10.1037//0022-0663.84.3.340

Spencer, S. L., \& Fitzgerald, J. (1993). Validity and structure, coherence, and quality measures in writing. Journal of Reading Behaviour, 25(2), 209-231. https://doi.org/10.1080/10862969309547811

Teberosky, A., \& Sepúlveda, A. (2009). El texto en la alfabetización inicial. Infancia y Aprendizaje, 32(2), 199-218. https://doi.org/10.1174/021037009788001770 
Torrance, M., Fidalgo, R., \& García, J. N. (2007). The teachability and effectiveness of cognitive self-regulation in sixth-grade writers. Learning and Instruction, 17, 265-285. https://doi.org/10.1016/j.learninstruc.2007.02.003

Torrance, M., Fidalgo, R., \& Robledo, P. (2015). Do sixth-grade writers need process strategies? British Journal of Educational Psychology, 85(1), 91-112. https://doi.org/10.1111/bjep.12065

Torrance, M., \& Galbraith, D. (2006). The processing demands of writing. In C. A. MacArthur, S. Graham, \& J. Fitzgerald (Eds.), Handbook of writing research (pp. 67-82). New York: Guildford Publications.

Tracy, B., Reid, R., \& Graham, S. (2009). Teaching Young Students Strategies for Planning and Drafting Stories: The Impact of Self-Regulated Strategy Development. The Journal of Educational Research, 102(5), 323-332. https://doi.org/10.3200/JOER.102.5.323-332

Zimmerman, B., \& Bandura, A. (1994). Impact of self-regulatory influences on the development of writing proficiency. American Educational Research Journal, 31, 845862. https://doi.org/doi.org/10.2307/1163397

Zumbrunn, S., \& Bruning, R. (2013). Improving the writing and knowledge of emergent writers : the effects of self-regulated strategy development. Reading and Writing, 26(1), 91-110. https://doi.org/10.1007/s11145-012-9384-5 
Tables and Figure

Table 1. Sample Characteristics

\begin{tabular}{llcc}
\hline Condition & Class & $\mathrm{N}(\mathrm{N}$ male $)$ & $\begin{array}{c}\text { Age at pre-test in } \\
\text { years, M (SD) }\end{array}$ \\
\hline Intervention $(\mathrm{N}=62)$ & Class A (School 1) & $16(10)$ & $6.5(.35)$ \\
& Class B (School 2) & $22(9)$ & $6.6(.28)$ \\
& Class C (School 2) & $24(11)$ & $6.7(.26)$ \\
Control $(\mathrm{N}=39)$ & Class D (School 1) & $16(9)$ & $6.5(.28)$ \\
& Class E (School 2) & $23(8)$ & $6.6(.24)$ \\
\hline
\end{tabular}


Table 2. Features of the Intervention and Control conditions

\begin{tabular}{lcc}
\hline & Intervention & Control \\
\hline Instructional content & + & \\
$\begin{array}{l}\text { Strategies for planning narrative content and } \\
\text { structure }\end{array}$ & + \\
Transcription skills & & + \\
Instructional approach & + & + \\
Writing practice & + & + \\
Motivational training & + \\
Strategy instruction supported by mnemonics & + \\
Teaching and modelling planning & + \\
Text assessment & + \\
Reading comprehension & + \\
Writing in a social context & + \\
\hline
\end{tabular}


Table 3. Correlations among outcome measures

\begin{tabular}{lccccc}
\hline & Structure & Coherence & Quality & Framework & Episodes \\
\hline Coherence & .78 & & & & \\
Quality & .80 & .88 & & & \\
Narrative framework & .38 & .31 & .35 & .24 & .27 \\
Episodic structure & .72 & .54 & .67 & .38 \\
Text length & .31 & .22 & .38 & .27 & \\
\hline
\end{tabular}

Note. Parameters from linear mixed effects models of scores from all test occasions with random intercepts for students and random slopes and intercepts for test occasion. 
Figure 1 Caption [figure submitted as separate pdf]: Mean observed scores on outcome variables, by condition and test occasion. Error bars represent $95 \%$ confidence intervals.

Figure 1 footnote: Note: Means and standard deviations by condition and time-of-task are also tabulated in Appendix C. 


\section{Appendix A: The Story Mountain mnemonic}

Simplified version of the "Story Mountain" that formed the basis of the intervention reported in this paper. The road connecting the houses is omitted, and some other non-essential details are omitted for clarity.

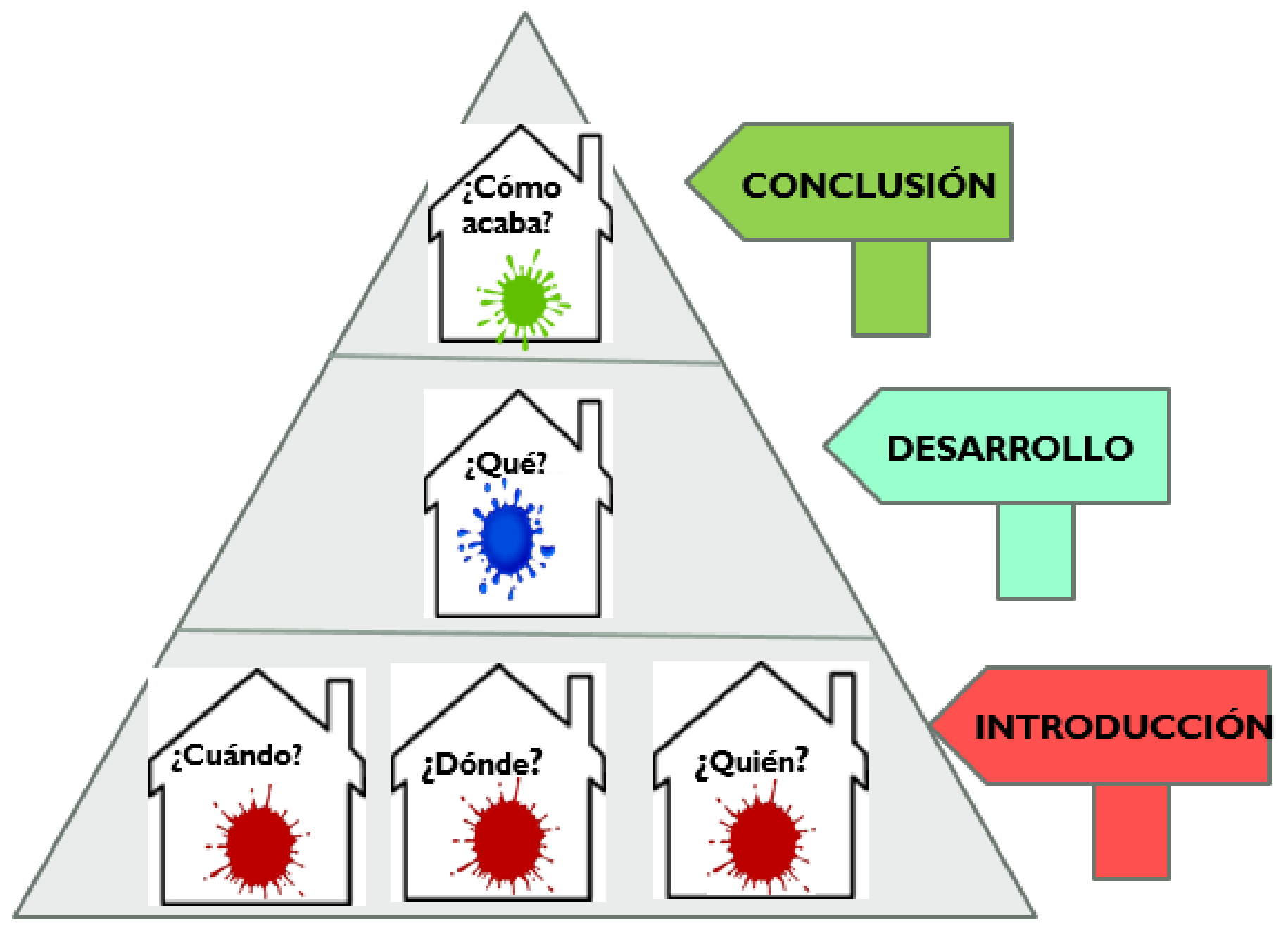




\section{Appendix B: Example Compositions}

The following three samples are intended as prototypes of students' compositions rated low, in the middle, and high on the three holistic quality dimensions. These were transcribed so as to preserve spelling and all other errors. For readability we have in some cases inserted spaces between words where these were omitted or were unclear in the handwritten originals. Underlining indicates words with omitted capitalisation and/or diacritics. Italics indicate spelling mistakes, including uninterpretable words.

We also provide an English translation. This reproduces capitalisation and punctuation errors from the original, and represents misspelt words with plausible English spelling errors.

\section{Text 1}

48 words. Structure $=1$, Coherence $=1$, Quality $=1$

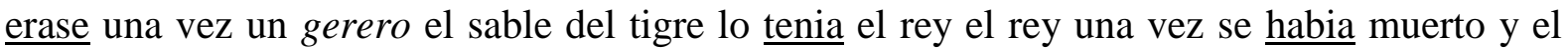
gerero tenia el sable lo tenia el gerero el otro tenia las pistolas y la gerera era veloz. el niño y la niña tenian un zorro.

once upon a time a warior the saber of the tiger the king had it the king one time was dead and the warior had the saber the warior had it another one had the pistols and the female warior was quick. the boy and the girl had a fox. 


\title{
Text 2
}

55 words. Structure $=3$, Coherence $=2$, Quality $=2$

Ace mucho en los 80 havia un roquero mas loco que una persona con una motosierra un dia estaba un fan de el le dijo si le firmaba un autografo $\underline{i}$ le dijo noooo $\underline{i}$ el fan se puso triste y el roquero le dijo que lla estas quoteto noo y el roquero se mata Fin

Log ago in the 80`s ther was a rock player crazier than a person with a chainsaw one day there was a fan of him and told him if he signed an authograph for him an he said noooo an the fan felt sad and the rock player told him if he was alredy hapy noo and the rock player killed himself The End

\section{Text 3}

57 Words. Structure $=4$, Coherence $=4$, Quality $=5$

\author{
El osito polar
}

Un día en el Polo Norte $\underline{a b i a}$ un osito polar. Y paso el tiempo con su mama. Pero cuando tuvo que ir al colegio y $s$ quedo triste y solo. Asta que en el recreo hizo un muñeco de nieve. Entonces sus compañeros decidierón ayudarle a mejorarlo. ¡Y hizo muchos amigos! Entonces fue feliz.

\section{The polar bear}

One day in the North Pole ther was a polar bear. And he spent time with his mommy. But when he had to go to school he felt sad and lonely. Util in the playground he made a snowman. Then his classmates decided to help him to improve it. And he made lots of friends! Then he was happy. 


\section{Appendix C: Supplementary Statistics}

Observed means by condition and test occasion. Standard deviations in parenthesis.

\begin{tabular}{lcccccc}
\hline & \multicolumn{2}{c}{ Pre-test } & \multicolumn{2}{c}{ Post-test } & \multicolumn{2}{c}{ Follow-up } \\
\hline \multirow{2}{*}{ Structure } & Control & Intervention & Control & Intervention & Control & Intervention \\
Coherence & $1.72(0.79)$ & $1.84(0.75)$ & $1.92(0.77)$ & $3.34(0.72)$ & $1.97(0.67)$ & $2.66(0.9)$ \\
Quality & $1.85(0.67)$ & $1.95(0.82)$ & $2.15(0.71)$ & $3.08(0.86)$ & $1.9(0.72)$ & $2.77(0.84)$ \\
Narrative framework & $2.03(0.93)$ & $2.1(0.97)$ & $2.15(0.74)$ & $3.34(1.01)$ & $2.05(0.72)$ & $2.94(0.99)$ \\
Episodic structure & $3.62(0.58)$ & $2.02(1)$ & $1.95(1.45)$ & $2.89(0.83)$ & $2.13(1.15)$ & $2.92(1.11)$ \\
Text length & $47.5(31.5)$ & $48.8(35.0)$ & $56.4(32.4)$ & $55.9(21.6)$ & $53.9(29.2)$ & $61.9(33.4)$ \\
\hline
\end{tabular}

Intra-class Correlation Estimates

\begin{tabular}{lcccc}
\hline & \multicolumn{2}{c}{ Pre and post test } & \multicolumn{2}{c}{ Pre and follow-up test } \\
\hline Structure & subject & class & subject & class \\
Coherence & 0.31 & 0.00 & 0.35 & 0.14 \\
Quality & 0.42 & 0.00 & 0.41 & 0.05 \\
Narrative framework & 0.37 & 0.05 & 0.36 & 0.18 \\
Episodic structure & 0.00 & 0.00 & 0.04 & 0.19 \\
Text length & 0.38 & 0.00 & 0.36 & 0.16 \\
\hline
\end{tabular}

Note: Values calculated from random effect and residual variance estimates taken from the linear mixed effects models described in the text. See Stram, D. O., \& Lee, J. W. (1994). Variance Components Testing in the Longitudinal Mixed Effects Model. Biometrics, 50(4), 1171-1177 for an explanation of the zero estimates. 
3.5

3.0

2.5

2.0

1.5

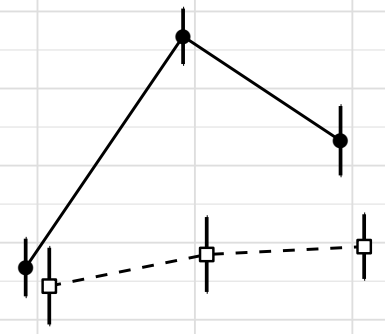

Pre

Post Follow-Up

\section{Quality}
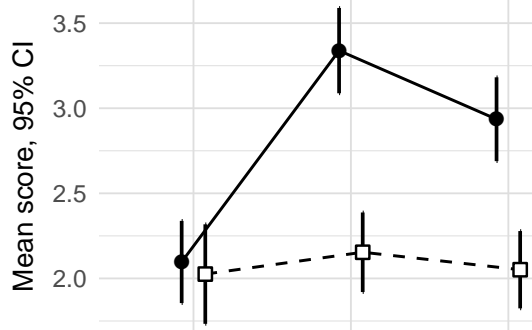

Pre

Post Follow-Up

\section{Episodes}

5

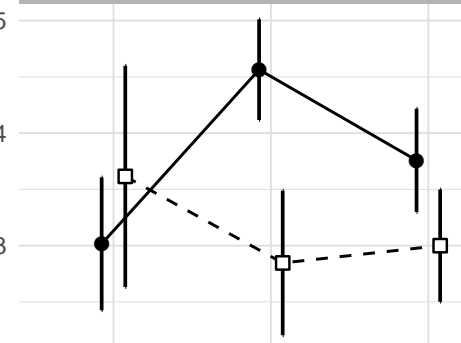

Pre Post Follow-Up
3.0

2.5

2.0

3.0

2.5

2.0

1.5

Pre

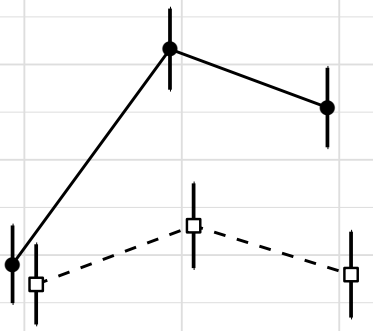

Post

Follow-Up

\section{Framework}

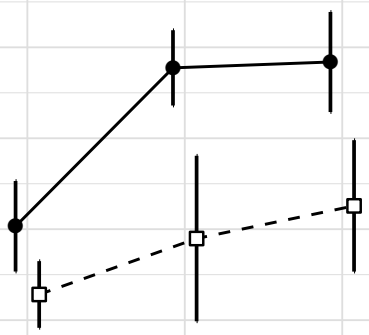

Pre

Post

Follow-Up

\section{Word Count}

70

60

50

40

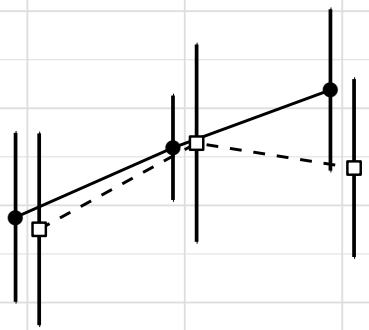

Pre

Follow-Up 